\title{
Ocular coloboma combined with cleft lip and palate: a case report
}

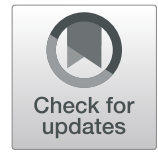

Yung Ju Yoo', Sang Beom Han ${ }^{1 *}$, Hee Kyung Yang ${ }^{2}$ and Jeong-Min Hwang ${ }^{2}$

\begin{abstract}
Background: Ocular coloboma is an excavation of ocular structures that occurs due to abnormal fusion of the embryonic optic fissure. Further, cleft lip/palate (CL/P), a congenital midline abnormality, is caused by a defect in the fusion of the frontonasal, maxillary, and mandibular prominences. No study has reported the association between these two phenotypes in the absence of other systemic abnormalities. We present a case of ocular coloboma along with CL/P and without other neurological abnormalities.

Case presentation: A 5-year-old Asian boy presented with decreased visual acuity in his right eye. Physical examination revealed no abnormal findings except $C L / P$, which was surgically corrected at the age of 9 months. Best-corrected visual acuity was 20/60 in the right eye and 20/25 in the left eye. Anterior segment examination revealed iris coloboma in the inferior quadrant of his right eye as well as a large inferonasal optic disc and chorioretinal coloboma in the same eye. He was prescribed glasses based on his cycloplegic refractive errors and part-time occlusion of the left eye was recommended. After 3 months, best-corrected visual acuity improved to 20/ 30 in the right eye.

Conclusion: The association of ocular coloboma should be kept in mind when encountering a patient with CL/P without other neurological or systemic abnormalities.
\end{abstract}

Keywords: Coloboma, Optic fissure closure, Cleft lip, Cleft palate, Case report

\section{Background}

Ocular coloboma is characterized by the absence of the iris, lens, retina, choroid, and/or optic nerve in the inferonasal quadrant of the eye and has variable phenotypes [1]. It occurs due to abnormal fusion of the embryonic optic fissure, which is normally completed by the sixth week of gestation [2,3]. Several studies have demonstrated that thalidomide, maternal vitamin A deficiency, toxoplasmosis, and cytomegalovirus infection can result in this condition [1]. Ocular coloboma may be associated with other developmental abnormalities, and there is a rare case of branchio-oculo-facial syndrome in which

\footnotetext{
* Correspondence: m.sangbeom.han@gmail.com

'Department of Ophthalmology, Kangwon National University Hospital, Kangwon National University School of Medicine, 156 Baengnyeong-ro, Chuncheon 24289, South Korea

Full list of author information is available at the end of the article
}

ocular coloboma, $\mathrm{CL} / \mathrm{P}$, branchial arches, and facial malformation are combined [4]. Although rarely reported, CL and choroidal coloboma can occur along with hypothalamopituitary dysfunction [5]. To the best of our knowledge, no study has reported ocular coloboma along with CL/P in a patient without other neurological abnormalities. Here, we report a recently encountered case of unilateral ocular coloboma with $\mathrm{CL} / \mathrm{P}$ and without other systemic abnormalities.

\section{Case presentation}

A 5-year-old Asian boy presented with decreased visual acuity in his right eye (Fig. 1). He was born with CL/P at 40 weeks of gestation. However, he had no family history of $\mathrm{CL} / \mathrm{P}$. His mother received a measles, mumps, and rubella vaccine during the first trimester of pregnancy. No relevant history of smoking, alcohol consumption, folate deficiency, exposure to ionizing radiation, or any

(c) The Author(s). 2020 Open Access This article is licensed under a Creative Commons Attribution 4.0 International License, which permits use, sharing, adaptation, distribution and reproduction in any medium or format, as long as you give appropriate credit to the original author(s) and the source, provide a link to the Creative Commons licence, and indicate if changes were made. The images or other third party material in this article are included in the article's Creative Commons licence, unless indicated otherwise in a credit line to the material. If material is not included in the article's Creative Commons licence and your intended use is not permitted by statutory regulation or exceeds the permitted use, you will need to obtain permission directly from the copyright holder. To view a copy of this licence, visit http://creativecommons.org/licenses/by/4.0/. The Creative Commons Public Domain Dedication waiver (http://creativecommons.org/publicdomain/zero/1.0/) applies to the data made available in this article, unless otherwise stated in a credit line to the data. 


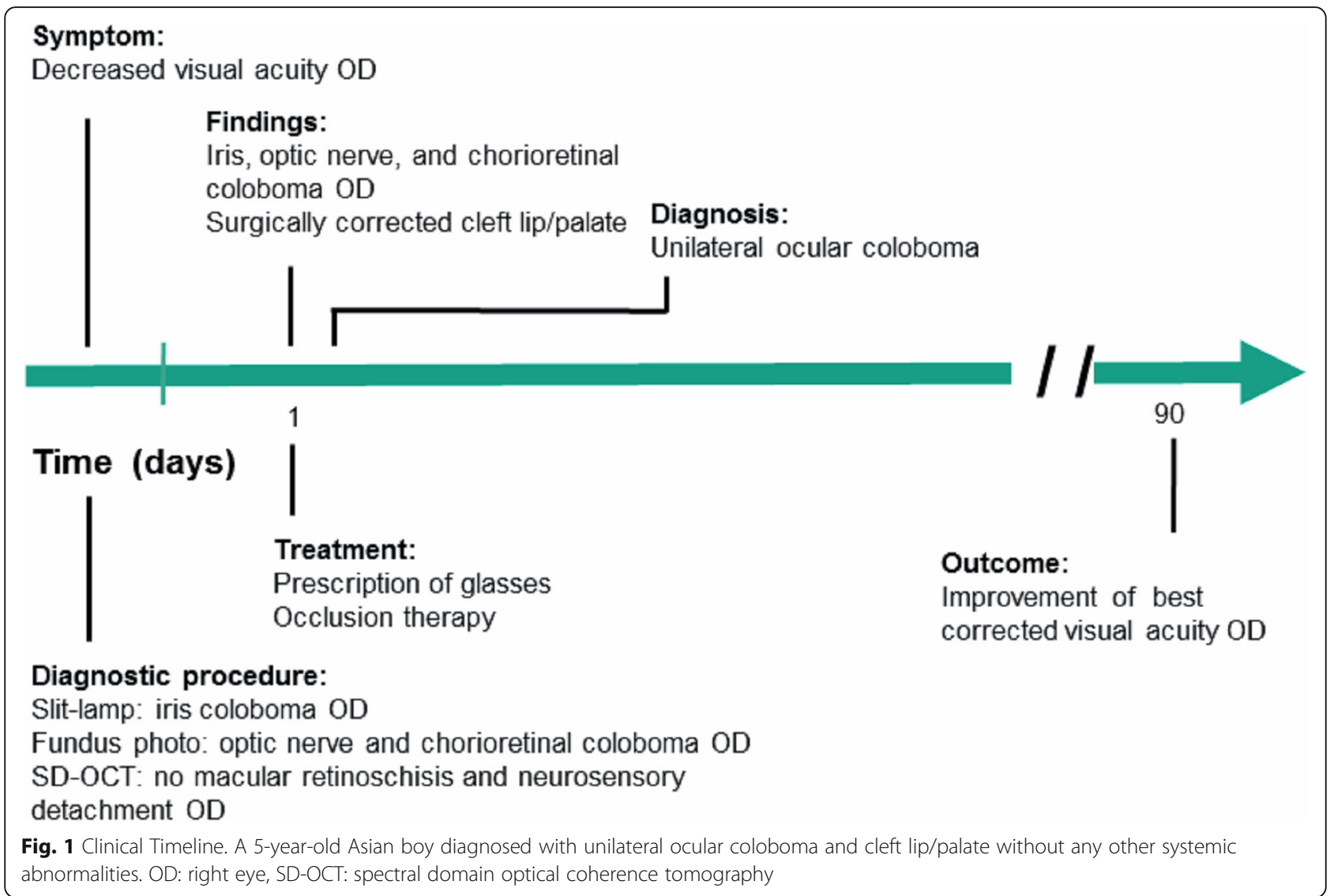

severe infection during pregnancy was found. Prenatal fetal ultrasonography showed unilateral $\mathrm{CL} / \mathrm{P}$ on the right side without brain lesions. Postnatal renal ultrasonography of the child revealed mild hydronephrosis in the right kidney without dysfunction. Follow-up examination at 4 years of age confirmed that both the kidneys were normal. He underwent several cardiological and endocrinological investigations for the evaluation of congenital rubella syndrome, which revealed no abnormal findings. Neurological examination revealed no midline defect of the vertebral bodies. At 9 months of age, he underwent successful surgical repair of his unilateral CL on the right side (Fig. 2a). He experienced two episodes of febrile seizures at the age of 2 years with no sequelae. Electroencephalography after the seizures revealed no remarkable findings. Although genetic analysis was recommended, his parents refused to undergo chromosomal evaluation. Magnetic resonance imaging showed no other midline defects or neurological anomalies. $\mathrm{He}$ did not have any intellectual or psychomotor developmental delays.

At initial presentation, his best-corrected visual acuity (BCVA) was 20/60 in the right eye and 20/25 in the left eye. Slit lamp examination revealed iris coloboma in the inferonasal quadrant of the right eye (Fig. 2b). Fundus examination showed optic nerve and chorioretinal colobomas in the inferonasal quadrant of the right eye (Fig. 2c and d). Spectral domain optical coherence tomography showed preserved foveal anatomy without retinoschisis or neurosensory detachment in the right eye (Fig. 2e). No evidence of microphthalmia, scleromalacia, congenital cataract, or ocular motility disorder was found. The left eye had no remarkable findings. He was prescribed glasses based on his cycloplegic refractive errors (Right eye: -2.00 Dsph -2.00 Dcyl $\times$ Axis $180^{\circ}$; Left eye: +1.50 Dsph -1.00 Dcyl $\times$ Axis $\left.180^{\circ}\right)$. We recommended daily occlusion therapy in the left eye for $4 \mathrm{~h}$. After 3 months, BCVA in the right eye improved to 20/30. In addition, the patient was referred to the otolaryngology department for otological and audiological assessments, which revealed no relevant abnormalities.

\section{Discussion and conclusions}

In our patient, unilateral ocular coloboma was associated with CL/P. However, no other neurological or systemic abnormalities were found. Previous studies have shown mutations in various genes associated with microphthalmia, anophthalmia, and coloboma (MAC) phenotypes [6]. However, none of these genes are considered a major causative gene of the MAC phenotype because 


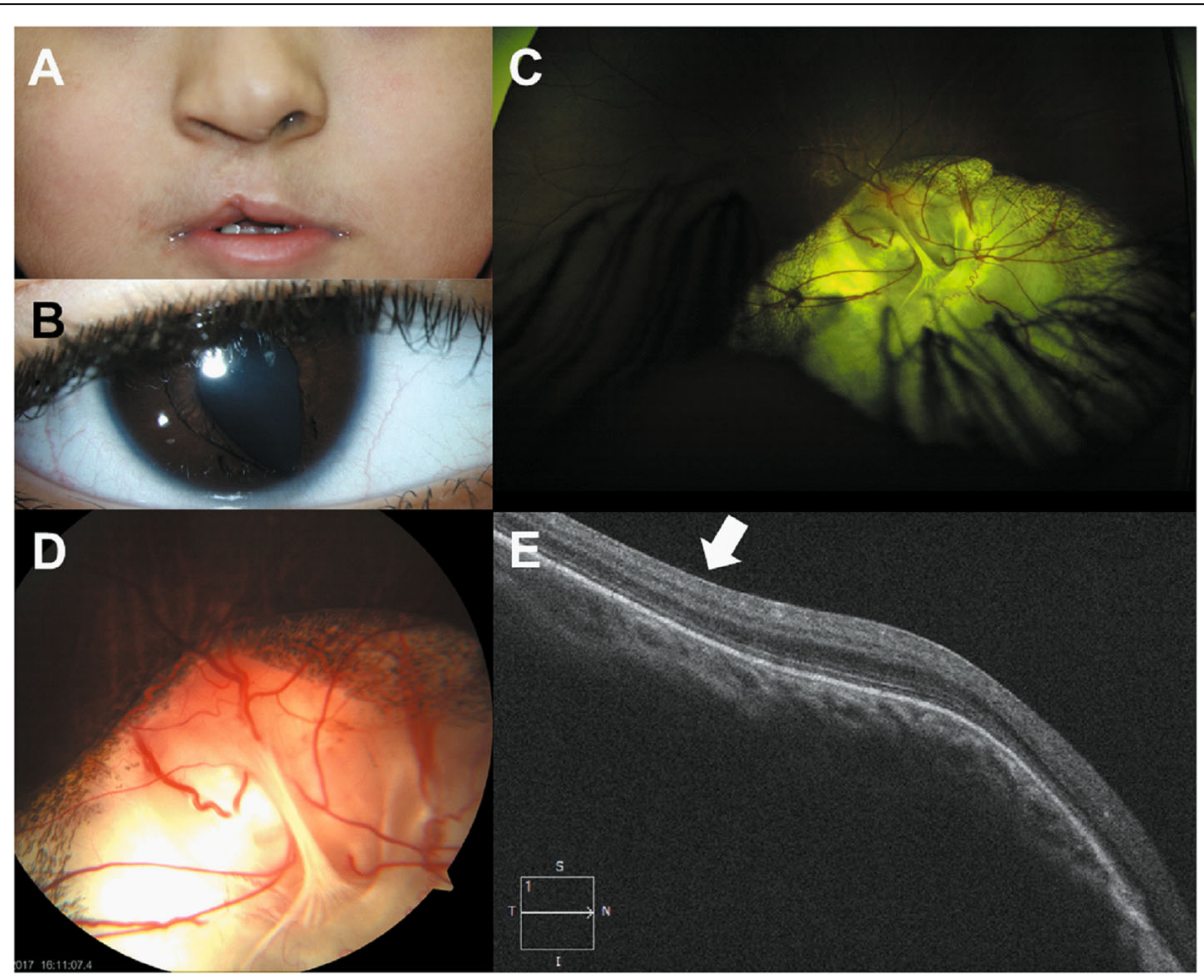

Fig. 2 Clinical photographs of case. a, Face photograph showed surgically corrected unilateral cleft lip on the right side. b, Right iris coloboma in the typical inferonasal position. $\mathbf{c}$ and $\mathbf{d}$, Fundus photograph of the right eye revealed coloboma of the optic disc, choroid and retina. $\mathbf{e}$, Horizontal spectral domain optical coherence tomography images of the right eye showed preserved foveal anatomy without retinoschisis or neurosensory detachment

each study found a definite mutation in only a small proportion of patients [6]. This reflects the heterogeneity of colobomatous deformities and the molecular complexity of ocular development. Our case revealed a unique association of unilateral ocular coloboma involving the iris, choroid, retina, and optic nerve with CL/P.

The co-existence of $\mathrm{CL} / \mathrm{P}$ and ocular coloboma in the absence of other congenital malformations did not match any previously reported syndromes related to known genetic loci [6]. By the end of the 6th week of gestation, the upper lip and primary palate are completely formed; this occurs by the fusion of the medial nasal processes followed by merging with the maxillary processes of both sides [7]. Shortly before these fusions are completed, a peak in cell division activity of the lateral nasal process, rendering it susceptible to teratogenic insults, is observed [7]. At this critical time point, the closure mechanism may fail if events that prevent growth occur. Regarding normal eye development, the fusion of the optic fissure begins at the center at approximately 5th week of gestation and advances anteriorly along the rim of the optic cup and posteriorly along the optic stalk [8]. The underlying etiology of ocular coloboma is failure to close the ectodermal optic vesicle fissure
[1]. Therefore, an insult during this period could result in the co-occurrence of these two anomalies.

Since rubella vaccine contains a live attenuated virus, which is a known teratogen, there might be concerns about fetal hazards occurring following vaccination during pregnancy [9]. However, prospective studies have revealed that rubella vaccination during pregnancy does not appear to affect pregnancy outcomes or cause congenital rubella syndrome [9]. We conducted a MEDL INE search for the association of maternal rubella vaccination with $\mathrm{CL} / \mathrm{P}$ and found no case of $\mathrm{CL} / \mathrm{P}$ associated with maternal rubella vaccination. A large-scale study involving six countries reported no association between $\mathrm{CL} / \mathrm{P}$ and vaccination of unaware women in the early stages of pregnancy [10]. The potential risk factors of CL/P include maternal smoking [11], maternal alcohol consumption [12], nutritional factors such as folate deficiency [13], exposure to ionizing radiation and infection [7], and maternal obesity [7]. In our case, the patient's mother confirmed that she was not exposed to any teratogenic risk factors during pregnancy.

$\mathrm{CL} / \mathrm{P}$ and coloboma co-exist in several conditions, many of which are associated with other systemic defects. The genes associated with syndromic forms of 
coloboma tend to be widely expressed and generally have a pleiotropic effect [14]. CHARGE syndrome (coloboma, heart disease, choanal atresia, retardation of growth and development, genitourinary malformations, and ear abnormalities) is a rare genetic condition that occurs during early fetal development that affects multiple organ systems [15]. A partial deletion of the short arm of chromosome 4 is observed in patients with Wolf-Hirschhorn syndrome [16]. Wolf-Hirschhorn syndrome is characterized by microcephaly, intellectual impairment, Greek helmet facies, and closure abnormalities such as ocular coloboma and cardiac septal defect [17]. However, our patient did not meet the diagnostic criteria of CHARGE syndrome or Wolf-Hirschhorn syndrome and systemic defects were not suspected based on the patient's diagnosis.

Our case is unique because extensive ocular coloboma and $\mathrm{CL} / \mathrm{P}$ co-existed without other neurological abnormalities. Branchio-oculo-facial syndrome caused by TFAP $2 A$ gene mutations is a condition that acts on prenatal development, especially the structures of the face and neck [4]. Features of this syndrome include skin abnormalities on the neck, eye and ear anomalies, and characteristic facial aspects [4]. However, in our case, no skin lesions such as brachial arches or characteristic facial deformities were noted. A case of CL and choroidal coloboma associated with endocrine abnormalities due to hypothalamic-pituitary dysfunction has been previously reported [5]. However, in our case, ocular coloboma was more extensive than previous reported cases and no endocrine abnormality associated with midline defects was noted.

Visual acuity in children with optic nerve coloboma is determined by the preservation of normal foveal anatomy [9]. The size of coloboma, optic nerve color change, or the presence of foveal pigmentation has no significant effect on central visual acuity [18]. Although significant refractive errors and anisometropia are common in patients with optic nerve coloboma, the most critical factor associated with good vision is the extent of foveal involvement of the coloboma [18]. Fortunately, preserved foveal structure in our patient led to a relatively good visual prognosis after correction with glasses.

In conclusion, we reported a case of ocular coloboma combined with $\mathrm{CL} / \mathrm{P}$ alone. This case indicates that in a patient with $\mathrm{CL} / \mathrm{P}$, attention should be paid to the possibility of ocular coloboma even in the absence of other systemic or neurological abnormalities.

\section{Abbreviations}

BCVA: Best-corrected visual acuity; CL/P: Cleft lip/palate;

MAC: Microphthalmia, anophthalmia and coloboma

Acknowledgements

Not applicable.

\section{Authors' contributions}

YJY contributed to data acquisition, data analysis, and manuscript drafting. $\mathrm{SBH}$ contributed to design of the work and manuscript revision. All authors read and approved the final manuscript. HKY contributed to manuscript drafting and manuscript revision. J-MH contributed to interpretation of data and manuscript revision. All authors read and approved the final manuscript.

\section{Funding}

This study was supported by 2020 Kangwon National University Hospital Grant and the Basic Science Research Program through the National Research Foundation of Korea (NRF) funded by the Ministry of Education (Grant no. NRF-2017R1D1A1B03029983). The funding body had no role in study design, data analysis, data interpretation, or manuscript writing.

\section{Availability of data and materials}

All data generated or analysed during this study are included in this published article.

\section{Ethics approval and consent to participate}

This study adhered to the Declaration of Helsinki and the protocol was approved by the Institutional Review Board of Kangwon National University Hospital. The parental consent was obtained with a signed consent form.

\section{Consent for publication}

The guardian of patient provided written consent for publication of the patient data and accompanying images in this case report.

\section{Competing interests}

Sang Beom Han is an Associate Editor in this journal. Other authors declare that they have no competing interests.

\section{Author details}

'Department of Ophthalmology, Kangwon National University Hospital, Kangwon National University School of Medicine, 156 Baengnyeong-ro, Chuncheon 24289, South Korea. ${ }^{2}$ Department of Ophthalmology, Seoul National University College of Medicine, Seoul National University Bundang Hospital, Seongnam, South Korea.

Received: 16 April 2020 Accepted: 13 October 2020

Published online: 19 October 2020

\section{References}

1. Gregory-Evans CY, Williams MJ, Halford S, Gregory-Evans K. Ocular coloboma: a reassessment in the age of molecular neuroscience. J Med Genet. 2004;41:881-91.

2. Dutton G. Congenital disorders of the optic nerve: excavations and hypoplasia. Eye. 2004:18:1038.

3. Duvall J, Miller SL, Cheatle E, Tso MO. Histopathologic study of ocular changes in a syndrome of multiple congenital anomalies. Am J Ophthalmol. 1987;103:701-5.

4. Raveh E, Papsin BC, Forte V. Branchio-oculo-facial syndrome. Int J Pediatr Otorhinolaryngol. 2000;53:149-56.

5. Zuppinger KA, Sutter M, Zurbrugg RP, Joss EE, Oetliker O. Cleft lip and chorioideal coloboma associated with multiple hypothalamo-pituitary dysfunctions. J Clin Endocrinol Metab. 1971;33:934-9.

6. Skalicky SE, White AJ, Grigg JR, Martin F, Smith J, Jones M, Donaldson C, Smith JE, Flaherty M, Jamieson RV. Microphthalmia, anophthalmia, and coloboma and associated ocular and systemic features: understanding the spectrum. JAMA Ophthalmol. 2013;131:1517-24.

7. Mossey PA, Little J, Munger RG, Dixon MJ, Shaw WC. Cleft lip and palate. Lancet. 2009;374:1773-85.

8. Graw J. The genetic and molecular basis of congenital eye defects. Nat Rev Genet. 2003;4:876

9. Keller-Stanislawski B, Englund JA, Kang G, Mangtani P, Neuzil K, Nohynek H, Pless R, Lambach P, Zuber P. Safety of immunization during pregnancy: a review of the evidence of selected inactivated and live attenuated vaccines. Vaccine. 2014:32:7057-64.

10. Castillo-Solórzano C, Reef SE, Morice A, Vascones N, Chevez AE, CastaliaSoares R, Torres C, Vizzotti C, CJJoid RM. Rubella vaccination of unknowingly pregnant women during mass campaigns for rubella and 
congenital rubella syndrome elimination, the Americas 2001-2008. J Infect Dis. 2011;204:S713-7.

11. Little J, Cardy A, Munger RG. Tobacco smoking and oral clefts: a metaanalysis. Bull World Health Organ. 2004;82:213-8.

12. Mossey P, Little J. Addressing the challenges of cleft lip and palate research in India. Indian J Plast Surg. 2009:42(Suppl):S9-S18.

13. Wehby GL, Murray JC. Folic acid and orofacial clefts: a review of the evidence. Oral Dis. 2010;16:11-9.

14. George A, Cogliati T. Brooks BPJEER: Genetics of syndromic ocular coloboma: CHARGE and COACH syndromes. Exp Eye Res. 2020;193:107940.

15. Hsu P, Ma A, Wilson M, Williams G, Curotta J, Munns CF. Mehr SJJop, health c: CHARGE syndrome: a review, vol. 50; 2014. p. 504-11.

16. Tutunculer F, Acunas B, Hicdonmez T, Deviren A, Pelitli V. Wolf-Hirschhorn syndrome with posterior intraorbital coloboma cyst: an unusual case. Brain Dev. 2004;26:203-5.

17. Seth A, Gupta R, Gupta A, Raina UK, Ghos B. Bilateral optic disc pit with maculopathy in a patient with cleft lip and cleft palate. Indian J Ophthalmol. 2015;63:346-8.

18. Olsen TW, Summers CG, Knobloch WH. Predicting visual acuity in children with colobomas involving the optic nerve. J Pediatr Ophthalmol Strabismus. 1996:33:47-51

\section{Publisher's Note}

Springer Nature remains neutral with regard to jurisdictional claims in published maps and institutional affiliations.

Ready to submit your research? Choose BMC and benefit from:

- fast, convenient online submission

- thorough peer review by experienced researchers in your field

- rapid publication on acceptance

- support for research data, including large and complex data types

- gold Open Access which fosters wider collaboration and increased citations

- maximum visibility for your research: over $100 \mathrm{M}$ website views per year

At BMC, research is always in progress.

Learn more biomedcentral.com/submissions 